\title{
Sensible heat flux and local advection over a heterogeneous landscape at an Arctic tundra site during snowmelt
}

\author{
P. Marsh, ${ }^{1}$ J.W. Pomeroy, ${ }^{1}$ N. Neumann ${ }^{1,2}$ \\ ${ }^{1}$ National Hydrology Research Institute, 11 Innovation Boulevard, Saskatoon, Saskatchewan S7.N 3H5, Canada \\ ${ }^{2}$ Department of Geography, Universily of Saskatchewan, Saskatoon, Saskatchewan S7.N.5A5, Canada
}

\begin{abstract}
During snowmelt over a continuous snow cover, the vertical turbulent exchanges of sensible and latent energy are influenced by regional air-mass characteristics, which exert a strong control on air temperature. In high-latitude sites, the melting surface rapidly becomes heterogeneous, with patches of snow and snow-free areas. Local advection occurs when near-surface air layers are warmed due to sensible heat flux from the snow-free areas, with the resulting heat transferred horizontally to adjacent snowpatches. This advection greatly increases the rate of snowmelt along the leading edges of the snow patches. In order to estimate correctly the average melt rates of the snowpatches and the bulk energy balance of the entire landscape, it is necessary to estimate the local advection component. To date, few studies have dealt with this problem. This paper reports results from an Arctic tundra site located approximately $55 \mathrm{~km}$ northeast of Inuvik, Northwest Territories, Canada. The importance of local advection is estimated by comparing the sensible heat flux of the snowpatches to estimates of sensible heat without local advection. This latter term is derived from a relationship between upper air temperature and sensible heat flux over a continuous snow cover. This work has important implications for developing models that correctly represent the cryosphere of tundra regions, and in developing appropriate scaling techniques for heterogeneous landscapes.
\end{abstract}

\section{INTRODUGTION}

The energy balance of continuous snow cover (Male and Gray, 1981) and the energy available from net radiation and the vertical turbulent exchange of energy are well known . The relative importance of each of these terms is highly variable, as illustrated by the summary of typical ranges in various environments provided by Kuusisto (1986). In areas or years where melt occurs before the "high sun" period of April or May, shortwave radiation inputs are relatively small and the sensible heat flux $\left(Q_{\mathrm{H}}\right)$ dominates the surface energy balance. Even when net radiation is strongly positive, the contribution of sensible heat is required to initiate largescale melting. Male and Granger (1981) showed that for snowpacks that are at low elevations and are shallow the "rate of melt is largely dependent on the energy content of the air mass present". Male and Granger (1981) also noted that Sverdrup (1936) classified the magnitude of sensible and latent heat turbulent fluxes by general weather conditions, but that since that time the impact of "energy and moisture contents of the air-mass properties have been generally overlooked".

In many shallow-snow environments (i.e. the prairies and the Arctic tundra) the surface snow-cover distribution at the end of winter is highly variable (Woo and others, 1983; Pomeroy and Gray, 1995) and as melt begins, the areas with the shallowest snow cover become snow free (Shook and Gray, 1994). The result is a surface with a complex distribution of snowpatches with intervening snow-free areas (Fig. 1). In this situation, the surface energy balance is compli- cated by the local advection of sensible heat from the snowfree areas to the snowpatches $\left(Q_{\mathrm{A}}\right)$ (Shook, 1995; Liston, 1995). This results in spatially variable melt, with melt enhanced at the upwind edges of snowpatches.

Since the distribution of air temperature, and therefore sensible heat flux to the snow surface, is spatially variable, it is difficult to use measurement of air-temperature gradients in the lower few metres of the atmosphere to estimate average sensible heat flux by flux-gradient relationships and therefore to average snowmelt over the patchy snow surface. This problem arises from the fact that steady-state, fully developed boundary layers do not exist near the surface, and so air temperature and sensible heat flux at any given point are dependent on the distribution of snow and snow-free patches in an upwind source area. The spatial patterns of these surfaces are constantly changing due to ongoing melt, and the size and orientation of the source area are dependent on wind direction and speed. Marsh and Pomeroy (1996) suggested that the average melt could be determined from estimates of energy fluxes for the melt of a large snowpatch that is unaffected by local advection $\left(Q_{\mathrm{HL}}\right)$ and by an estimate of local advection. This local advection term could be estimated from a knowledge of the sensible heat flux from the snow-free areas $\left(Q_{\mathrm{H}_{\mathrm{B}}}\right)$, the snow-covered area, and $F_{\mathrm{S}}$, a function expressing the portion of the bare-area sensible heat flux $\left(Q_{\mathrm{H}_{\mathrm{B}}}\right)$ that is advected to snowpatches.

To date, changes in $Q_{\mathrm{HL}}$ and $F_{\mathrm{S}}$ have not been documented during the melt of a patchy snow cover. One potential method to estimate $Q_{\mathrm{HL}}$ is based on the work of Male and Granger (1981), who illustrated the impact of local advection 


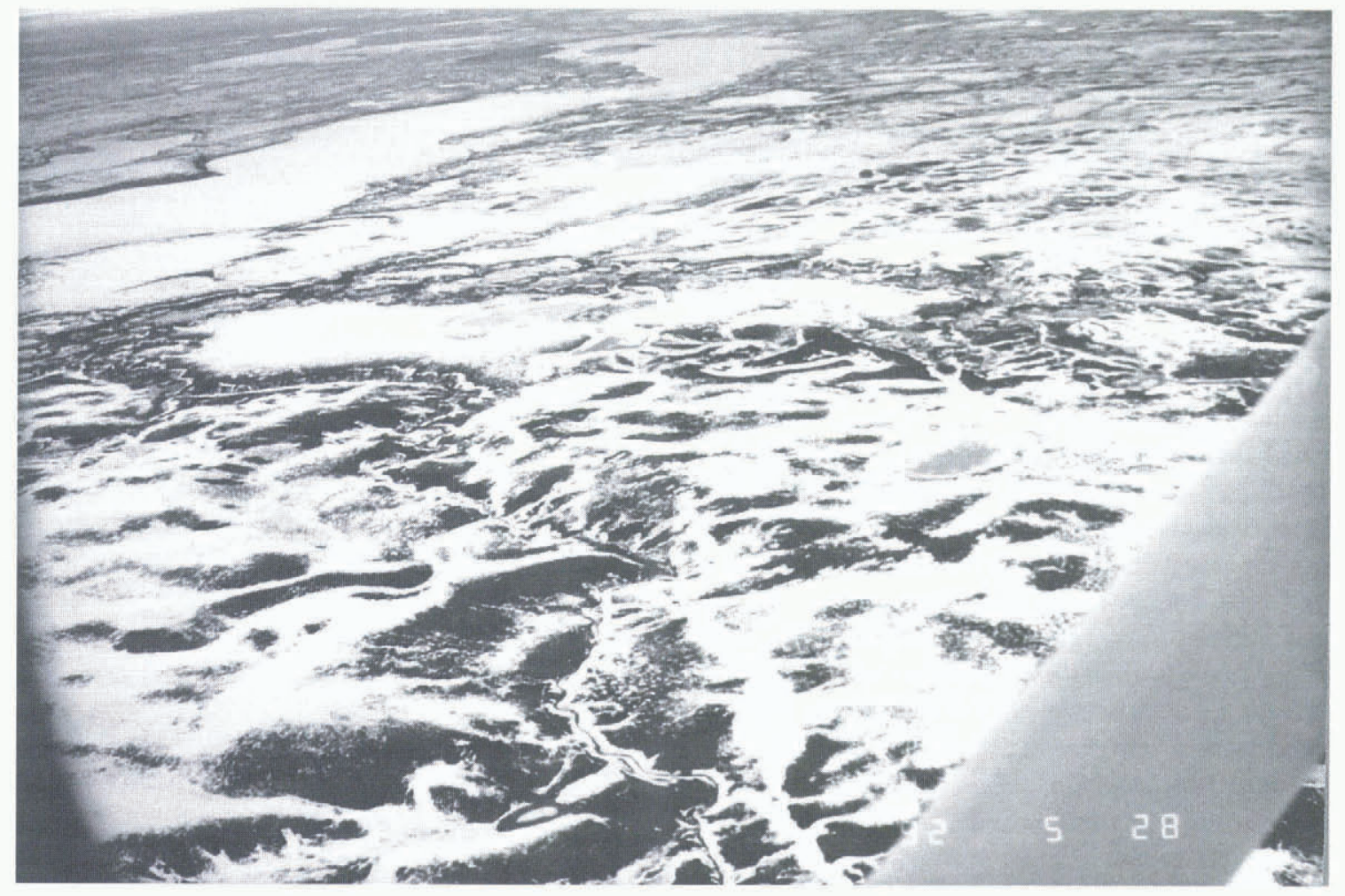

Fig. I. An example of the patchy snow cover typical of the melt period in Arctic tundra regions. Trail Valley Creek, 28 May 1992.

by comparing sensible heat flux to upper-air temperatures. They found that the sensible heat flux for patchy snow cover was considerably larger than that for a continuous snow cover, even though the air-mass characteristics as indicated by the $850 \mathrm{mb}$ air temperature were similar. The increase in sensible heat must therefore be due to local advection.

The purpose of this paper is to carry out an initial investigation of the relationship between upper-air temperature and sensible heat flux to the snow cover at a tundra site, in order to estimate the role of local advection in the melt of patchy snow covers.

\section{STUDY AREA AND METHODOLOGY}

During the spring of 1993 , field studies were carried out at Trail Valley Creek $\left(68^{\circ} 45^{\prime} \mathrm{N}, 133^{\circ} 30^{\prime} \mathrm{W}\right)$, located approximately $55 \mathrm{~km}$ north-northeast of Inuvik, Northwest Territories (N.W.T.) in the forest-tundra transition. Trail Valley Creek is approximately $63 \mathrm{~km}^{2}$ in area, with elevations ranging from 60 to $190 \mathrm{~m}$ a.s.l. The climate is characterized by short, cool summers, long, cold winters, and low precipitation, much of which occurs as snow. Landscape classes were mapped for the Trail Valley Creek area, and are described by Marsh and Pomeroy (1996). The landscape in this area comprises lakes $(<1 \%)$, tundra $(70 \%)$, shrub tundra $(21 \%)$, forest $(<1 \%)$, and steep slopes, channel systems, and lake edges that accumulate deep snowdrifts $(8 \%)$.

Sensible heat flux over snow cover was estimated using the bulk-aerodynamic method (Dunne and others, 1976). Details are provided in Marsh and Pomeroy (1996). During the period of patchy snow cover, estimates of sensible heat flux are undoubtedly enhanced by local advection. Following standard practice in the snow research community, sensible heat flux is considered to be positive when the flux is directed towards the snow surface. Changes in snow- covered area during the melt period were obtained from aerial photographs (Marsh and Pomeroy, 1996).

Upper-air temperature for the $850 \mathrm{mb}$ level (approximately $1400 \mathrm{~m}$ a.s.l.), were obtained from the Atmospheric Environmental Service (Canada) (AES) weather station located near Inuvik airport, approximately $55 \mathrm{~km}$ from the Trail Valley Creek research site. These measurements are taken twice daily at 00.00 and 00.12 h U.T,

\section{RESULTS}

Comparison of near-surface and upper-air temperatures

Figure 2 shows the $850 \mathrm{mb}$ air temperature from the Inuvik upper-air station and the air temperature at approximately

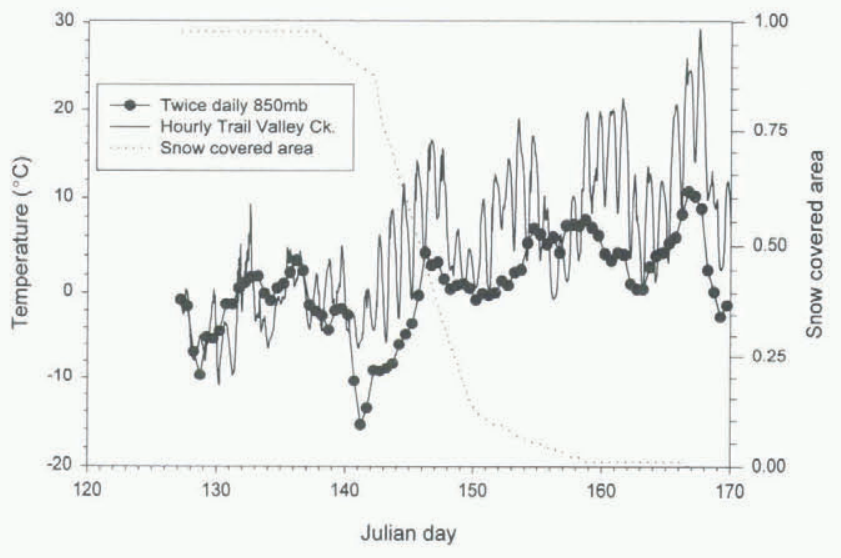

Fig. 2. Comparison of Trail Valley Creek air temperatures at approximately $1 \mathrm{~m}$ level, and from the Inuvik Upper Air Station at the $850 \mathrm{mb}$ level. Also shown is the change in snow cover in the Trail Valley Creek area. 
$1 \mathrm{~m}$ above the snow surface at Trail Valley Creek. Also shown is the change in snow-covered area over the $1993 \mathrm{melt}$ period. Up to Julian Day (JD) 138, the research site was nearly completely snow covered. During this period, the $850 \mathrm{mb}$ air temperature and the near-surface air temperature were very similar (Fig. 2). A major difference between the two records is the occurrence of large diurnal variations in near-surface temperature. As the snow cover decreased in area after.JD 138, the similarity between temperature declined, with the near-surface air temperature consistently higher than the upper-air temperature (Fig. 2).

The two temperature records diverged markedly after JD 140, when the $850 \mathrm{mb}$ temperature decreased significantly, but the near-surface temperature did not. This change in the relationship between near-surface and $850 \mathrm{mb}$ air temperature is likely to be related to changes in the local source of energy to the lower atmosphere. As the snow-surface temperature remains no higher than $0^{\circ} \mathrm{C}$ during the snowmelt period, the sensible heat flux is always downward from the air (warmer than $0^{\circ} \mathrm{C}$ ). Hence, sensible heat flux over the snow-covered area cannot explain the sustained warming of the near-surface air temperature whilst the upper air cooled. The source of energy for warming the near-surface layer of air is therefore presumed to be advection of the sensible heat flux from snow-free areas. Snow-free zones sustained surface temperatures higher than the air temperature, and developed a sensible heat flux capable of warming the near-surface layer of air. Other sources of energy to warm the near-surface air include vegetation canopies over snow surfaces. These areas include nearby forest patches and shrub areas. In addition, there may be mesoscale advection of sensible heat from forested areas to the south and west. The closest treed areas are about $40 \mathrm{~km}$ to the south and $25 \mathrm{~km}$ to the west on the Mackenzie Delta. The relative importance of these more remote sources of energy is unknown, but it is felt that the local source of energy from the snow-free patches dominates.

\section{Comparison of upper-air temperature and snow sensible heat flux}

Figure 3 a shows the time series for both the sensible heat flux to the snowpatches as described by Marsh and Pomeroy (1996) for the 1993 study period, and the $850 \mathrm{mb}$ air temperature. During the period when snow cover was $>95 \%$ (up to JD 136), the calculated sensible heat flux was always low in value (Fig. 3a), and was only slightly higher than that estimated by Male and Granger (1981) for similar $850 \mathrm{mb}$ air temperatures in the Canadian Prairies as shown by the solid curve in Figure 3b. Since the relationship shown in the work of Male and Granger (1981) is empirical, and the Trail Valley Creek terrain is more rugged than Saskatchewan prairie with a resulting increase in turbulence, the larger sensible heat flux for the same upper-air temperature at Trail Valley Creek compared to the Prairies is not unexpected. Also shown on Figure $3 \mathrm{~b}$ is a modified version of the Male and Granger (1981) equation. This equation has the same shape as that devised by Male and Granger, but predicts slightly higher sensible heat flux for a given $850 \mathrm{mb}$ temperature, thereby providing a better fit to the measured data for the Inuvik area.

After the snow cover began to decrease in area, the calculated sensible heat flux began to increase (Fig. 3a), and when plotted against mean daily $850 \mathrm{mb}$ air temperature
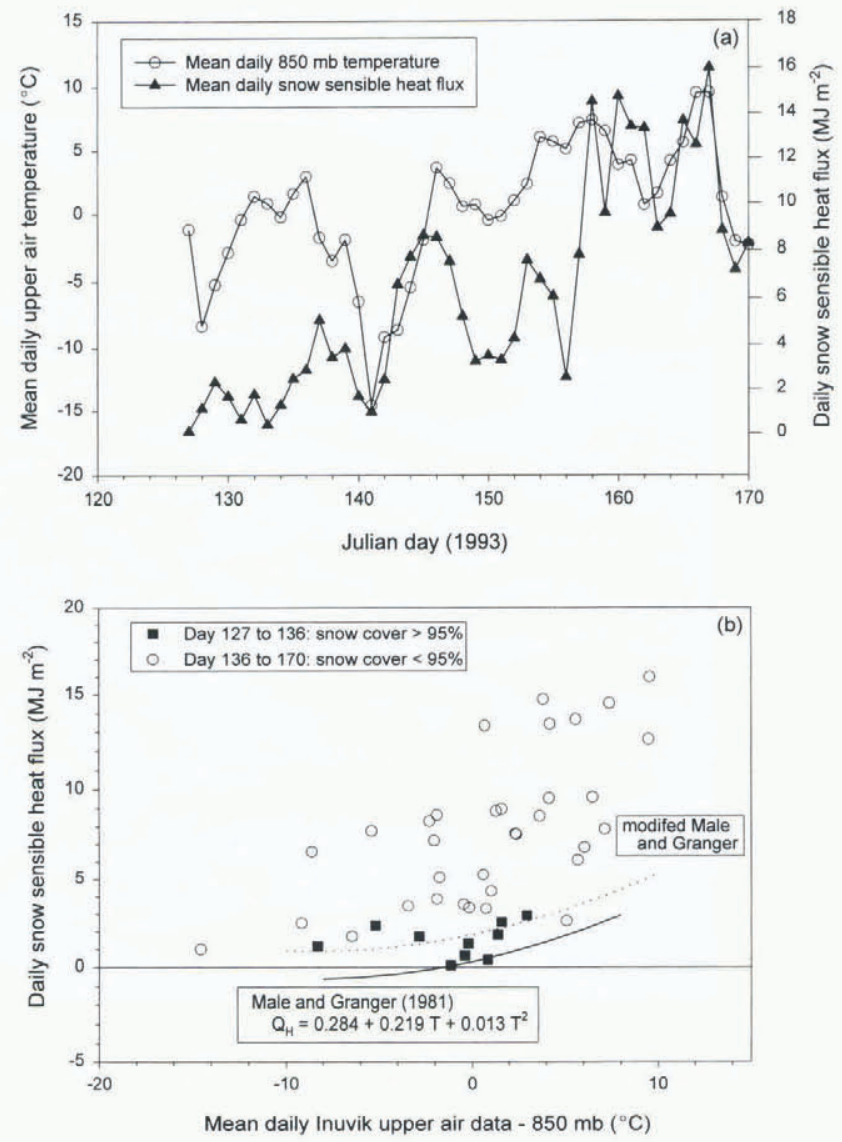

Fig. 3. (a) Comparison of the mean daily $850 \mathrm{mb}$ air temperature and the daily sensible heat flux for snow-covered surface at Trail Valley Creek. Sensible heat flux was calculated using the bulk-aerodynamic method (Marsh and Pomeroy, 1996). (b) Relationship between mean daily Inuvik $850 \mathrm{mb}$ temperature and snow-surface sensible heat flux for Trail Valley Creek.

(open circles on Fig. 3b) the sensible flux was consistently higher than for similar $850 \mathrm{mb}$ temperatures during the period with a snow cover $>95 \%$. Drawing on the evidence provided by Male and Granger (1981), it seems likely that the higher sensible heat fluxes during the period with patchy snow cover are due to the local advection of sensible heat from the bare patches.

\section{Relationship between snow-free sensible heat and local advection to the snow}

Figure 4 a shows the sensible heat flux to the snowpatches as calculated by Marsh and Pomeroy (1996) and as calculated using the modified empirical relationship between sensible heat and $850 \mathrm{mb}$ air temperature as determined by Male and Granger (1981). For the first part of the study period, the sensible heat flux estimated by both methods is similar. However, as the snow-free area begins to increase, the sensible heat flux from the bulk-aerodynamic method begins to increase dramatically. It is hypothesized that the difference between these fluxes is due to local advection with the magnitude of the local advection calculated by:

$$
Q_{\mathrm{A}}=Q_{\mathrm{H}}-Q_{\mathrm{HM} \text { and } \mathrm{G}}
$$

where $Q_{\mathrm{A}}$ is local advection, $Q_{\mathrm{H}}$ is the sensible heat to the snow as calculated by Marsh and Pomeroy (1996) using the bulk-aerodynamic method, and $Q_{\mathrm{HM} \text { and } \mathrm{G}}$ is the sensible heat flux to a large snowpatch that is not affected by local advection as estimated from the modified Male and Gran- 

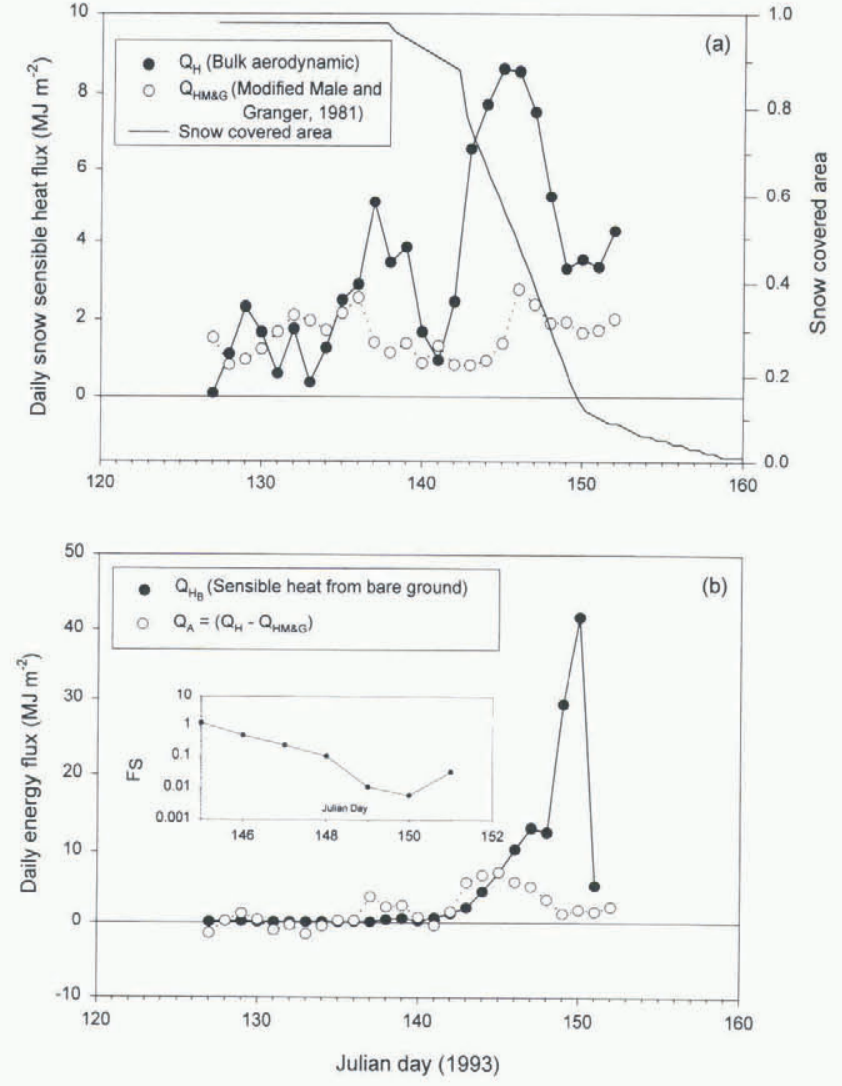

Fig. 4. (a) Comparison of the snow-surface sensible heat flux calculated from the bulk-aerodynamic method (Marsh and Pomeroy, 1996) and using the modified relationship between $850 \mathrm{mb}$ air temperature and sensible heat flux. (b) Comparison of the sensible heat flux from the snow-free areas as determined by Marsh and Pomeroy (1996) and the calculated $Q_{\mathrm{A}}$ (Equation (1)). The insert shows the calculated $F_{\mathrm{S}}$.

ger (1981) equation. As Figure 4b shows, $Q_{\mathrm{A}}$ is similar in magnitude to the sensible heat flux from the snow-free areas calculated by Marsh and Pomeroy (1996) up to JD 145. After this time, the sensible heat flux from the snow-free areas increases dramatically.

As suggested by Marsh and Pomeroy (1996), the sensible heat from bare patches is used to warm the lower layers of the atmosphere, and a portion of this energy is advected laterally to the snow patches, resulting in increased melt along the upwind edges of the snowpatches. The portion of this energy that is used to melt the snow cover is related to the size and distribution of the snowpatches. It would be expected that all the advected energy is used to enhance melt early in the melt period, and only a small portion of the energy enhances melt later in the melt period. Marsh and Pomeroy (1996) suggested that a portion of the snowfree areas' sensible heat flux, which is advected (per unit snow-covered area) to the snowpatches $\left(Q_{\mathrm{A}}\right)$ may be estimated as:

$$
Q_{\mathrm{A}}=\left(\frac{Q_{\mathrm{H}_{\mathrm{B}}} P_{\mathrm{B}}}{P_{\mathrm{S}}}\right)\left(F_{\mathrm{S}}\right)
$$

where $P_{\mathrm{B}}$ and $P_{\mathrm{S}}$ represent the snow-free and snow-covered fractions of the basin, respectively, $Q_{\mathrm{H}_{\mathrm{B}}}$ is the sensible heat flux from those parts of the basin that are snow free, and $F_{\mathrm{S}}$ is a function expressing the portion of the bare area $\left(Q_{\mathrm{H}_{\mathrm{B}}}\right)$ that is advected to the snowpatches. Assuming no mesoscale advection, $F_{\mathrm{S}}$ would have a value between 0 and 1 , depending on the relative portion of bare vs snow-covered area, wind speed, terrain roughness, upwind bare fetch length, and the perimeter-to-area ratio of snow patches.

Given the data on $Q_{\mathrm{H}}, Q_{\mathrm{H}_{\mathrm{B}}}, P_{\mathrm{S}}$, and $Q_{\mathrm{A}}$ given in Figure $4, F_{\mathrm{S}}$ may be calculated by rearranging Equation (2). The results shown in Figure 4 indicate that $F_{\mathrm{S}}$ decreases in time after JD 145 (the date when advection from sensible heat from bare ground and the estimate of local advection from aerodynamic method diverge). From JD 145 (snow-covered area $=60 \%) F_{\mathrm{S}}$ declines from 1 . This is the point of maximum snowmelt rate and, as the $F_{\mathrm{S}}=1$ and the snow-free area is large, is the maximum "efficiency" in the regional energetics of snowmelt. From JD 146 to 149, the value of $F_{S}$ continues to decrease from 0.48 to 0.01 . This implies that the portion of the advected energy that is used to enhance melt decreases dramatically as the basin snow-covered area declines from 50 to $20 \%$.

\section{CONCLUSIONS}

The relative importance of large-scale vs small-scale advection in driving the sensible heat flux during snowmelt in the low Arctic has been established. In the phases of premelt and early-melt, the near-surface and $850 \mathrm{mb}$ boundary-layer temperatures are well coupled, and the small sensible heat flux is driven by large or mesoscale advection of energy, imported by air masses to the Arctic region. This sensible heat can be linked to upper-air temperatures following a regional modification of an empirical scheme proposed for the prairie environment by Male and Granger (1981). As the snow-covered area declines below 95\%, air temperatures near the surface and at the $850 \mathrm{mb}$ level become decoupled as the near-surface boundary layer becomes non-steady due to the heterogeneous snow surface. The vertical sensible heat flux for these conditions exceeds that estimated due to advection of large-scale air masses.

Low albedo snow-free surfaces, heated by high net radiation inputs, provide a large near-surface energy source that drives the sensible heat flux over remaining snowpatches. All this energy is advected to the snowpatches until the snow-covered area declines below $60 \%$. There is a rapid decline in the proportion of available energy from bare ground advected to snow from about $50 \%$ advection at $50 \%$ snow cover, down to $1 \%$ at $10 \%$ snow cover. Though sensible heat is still large and driven by advection, the extremely large snow-free surface provides most of its available energy for heating the atmosphere, but very little to melting snow. The results provide an initial understanding necessary to coupling small-scale energy balance snowmelt models with larger-scale atmospheric models, and can form the basis for scaling techniques to link global climate models to land-surface process models for snow.

\section{ACKNOWLEDGEMENTS}

This work was supported by the National Hydrology Research Institute, the Canadian GEWEX Programme, the Polar Continental Shelf Project, the Science Institute of the Northwest Territories, and Indian and Northern Affairs Canada. We would like to thank C. Onclin, A. Dalton, K. Dion, J. Onclin, B. Quinton, K. Shook and R. Reid for their help in the field and with data reduction. 


\section{REFERENCES}

Dunne, T., A. G. Price and S. C. Colbeck. 1976. The generation of runoff from subarctic snowpacks. Water Resour. Res., 12 (4), 677-685.

Kuusisto, E. 1986. The energy balance of a melting snow cover in different cnvironments. International Association of Hydrological Sciences Publication 155 Symposium at Budapest 1986-Modelling Snowmell-Induced Processes), $37-45$.

Liston, G. E. 1995. Local advection of momentum, heat, and moisture during the melt of patchy snow covers. f. Appl. Meteorol., 34 (7), 1705-1715.

Male, D. H. and R.J. Granger. 1981. Snow surface energy exchange. Water Resour. Res., 17 (3),609-627.

Male, D. H. and D. M. Gray. 1981. Snowcover ablation and runoff. In Gray, D. M. and D. H. Male, eds. Handbook of snow: principles, processes, management and use. Toronto, Ont., Pergamon Press Canada Ltd., 360 436.
Marsh, P. and J.W. Pomeroy. 1996. Meltwater fluxes at an Arctic foresttundra sitc. Hydrol. Processes, 10, 1383-1400.

Pomeroy, J.W. and D. M. Gray. 1995. Snowcover: accumulation, relocation and management. Saskatoon, Sask., Environment Canada. National Hydrology Research Institute. (NHRI Science Report 4.)

Shook, K. R. 1995. Simulation of the ablation of prairie snowcovers. (Ph.D. thesis, University of Saskatchewan.)

Shook, K. and D. M. Gray. 1994. Determining the snow water equivalent of shallow prairie snowcovers. Proc. East. Snow Conf., 5lst Annual Meeting, 15-16 June 1994, Dearborn, Michigan, 89-95.

Sverdrup, H. U. 1936. The eddy conductivity of the air over a smooth snow field. Results of the Norwegian-Swedish Spitsbergen Expedition in 1934. Geofys. Publ., 11 (7), $1-69$.

Woo, M. -K., R. Heron, P. Marsh and P. Steer. 1983. Comparison of weather station snowfall with winter snow accumulation in High Arctic basins. Atmosphere-Ocean, 21 (3), 312-325. 